\title{
Hyper Zagreb indices of composite graphs
}

\author{
Sharmila devi.G ${ }^{1 *}$ and Kaladevi. ${ }^{2}$ \\ ${ }^{1}$ Research Scholar, Research and Development Centre, Bharathiar University, Coimbatore. Department of Mathematics, Kongu Arts and \\ Science college(Autonomous), Erode, India. \\ ${ }^{2}$ Department of Mathematics, Bishop Heber College, Trichy, India \\ *Corresponding author E-mail:sharmilashamritha@gmail.com
}

\begin{abstract}
For a(molecular)graph, the first zagreb index $M_{1}$ is equal to the sum of squares of the degrees of vertices the second zagreb index $M_{2}$ is equal to the products of the degrees of pairs of adjacent vertices. Similarly, the hyper zagreb index is defined as $H M(G)=\sum_{u v \in E(G)}\left(d_{G}(u)+d_{G}(v)\right)^{2}$. In this paper, First we obtain the hyper zagreb indices of some derived graphs and the generalized transformations graphs. Finally, the hyper zagreb indices of double, extended double, thorn graph, subdivision vertex corona graphs, splice
\end{abstract} and link graphs are obtained.

Keywords: Composite graphs, Hyper Zagreb Index

\section{Introduction}

All the graphs considered in this paper are connected and simple. For a vertex $u \in v(G)$, the degree of the vertex $\mathrm{u}$ in $\mathrm{G}$, denoted by $d_{G}(u)$, is the number of edges incident to $\mathrm{u}$ in $\mathrm{G}$. A topological index of a graph is a parameter related to the graph. It does not depend on labeling or pictorial representation of the graph. In theoretical chemistry, molecular structure descriptors (also called topological indices) are used for modeling physicochemical, pharmacologic, toxicologic, biological and other properties of chemical compounds[2]. Several types of such indices exist, especially those based on vertex and edge distances. One of the most intensively studied topological indices is the wiener index. Two of these topological indices are known under various names, the most commonly used ones we the first and second zagreb indices.

The zagreb indices have been introduced more than thirty years ago by Gutman and Trinajestic[3]. They are defined as $M_{1}(G)=$

$\sum_{u \in v(G)} d_{G}(u)^{2}, M_{2}(G)=\sum_{u v \in E(G)} d_{G}(u) d_{G}(v)$. Note that the first zagreb index may also written as $M_{1}(G)=\sum_{u v \in E(G)}\left(d_{G}(u)+d_{G}(v)\right)$. the zagreb indices are found to have applications in QSPR and QSAR studies as well, see[1]. The hyper zagreb index is defined as $H M(G)=\sum_{u v \in E(G)}\left(d_{G}(u)+d_{G}(v)\right)^{2}$.

For the survey on theory and application of zagreb indices see [6]. Feng et al.[5] have given a sharp bounds for the zagreb indices of graphs with a given matching number. Khalifeh et al.[4] have obtained the zagreb indices of the cartesian product, composition, joint, disjunction and symmetric difference of graphs. Ashrafi et al[8] determined the extremal values of zagreb coindices over some special class of graphs. Hua and Zhang [10] have given some rela- tions between zagreb coindices and some other topological indices Ashrafi et al.[7] have obtained the zagreb indices of the cartesian product, composition, joint, disjunction and symmetric difference of graphs. shirdel et al.[11], have obtained the hyper-zagreb indices of the cartesian product, join, composition and disjunction of graphs. The hyper zagreb indices of some classes of chemical graphs are obtained in $[11,13,14]$. In this paper, we compute the hyper zagreb indices of double, extended double, thorn graph, subdivision vertex corona of graphs. Next,we obtain the hyper zagreb indices of generalized transformations graphs and some derived graphs.

\subsection{Some Derived Graphs}

In this section, the hyper Zagreb indices of the following derived graphs are computed.

(i) The subdivision graph $S(G)$ is the graph obtained from $G$ by replacing each edge of $G$ by a path of length two.

(ii) The edge-semitotal graph $T_{1}(G)$ is obtained from $G$ by inserting a new vertex into each edge of $G$, then joining with edges those pairs of new vertices on adjacent edges of $G$.

(iii) The vertex-semitotal graph $T_{2}(G)$ is obtained from $G$ by adding a new vertex corresponding to each edge of $G$, then joining each new vertex to the end vertices of the corresponding edge.

(iv) The total graph $T(G)$ has as its vertices the edges and vertices of $G$. Adjacency in $T(G)$ is defined as adjacency or incidence for the corresponding elements of $G$

(v) The line graph of $G$, denoted by $L(G)$, is the graph whose vertices correspond to the edges of $G$ with two vertices being adjacent if and only if the corresponding edges in $G$ have a vertex in common.

\section{Lemma 1.1}

Let $G$ be a graph on $p$ vertices and $q$ edges. Then $H M(S(G))=$ 
$F(G)+M_{1}(G)+8 q$.

Proof. Observe that $V(S(G))=(V(S(G)) \cap V(G)) \cup(V(S(G)) \backslash$ $V(G))$, that is $|V(S(G))|=p+q$ and $|E(S(G))|=2 q$. Note that for $x \in V(S(G)) \cap V(G), d_{S(G)}(x)=d_{G}(x)$ and for $x \in V(S(G)) \backslash V(G)$, $d_{S(G)}(x)=2$. The hyper Zagreb index is given by,

$$
\begin{aligned}
H M(S(G)) & =\sum_{x y \in E(S(G))}\left(d_{S(G)}(x)+d_{S(G)}(x)\right)^{2} \\
& =\sum_{x \in V(S(G))}\left(d_{S(G)}(x)+2\right)^{2} \\
& =\sum_{x \in V(G)} d_{G}(x)\left(d_{G}(x)+2\right)^{2} . \\
& =\sum_{x \in V(G)}\left(d_{G}^{3}(x)+4 d_{G}^{2}(x)+4 d_{G}(x)\right) \\
& =F(G)+M_{1}(G)+8 q .
\end{aligned}
$$

\section{Lemma 1.2}

Let $G$ be a graph on $p$ vertices and $q$ edges. Then $H M\left(T_{2}(G)\right)=$ $4 H M(G)+4 F(G)+8 M_{1}(G)+8 q$.

Proof. From the definition of $T_{2}(G)$, it is observed that, for $x \in V\left(T_{2}(G)\right) \cap V(G), \quad d_{T_{2}(G)}(x)=2 d_{G}(x)$ and for $x \in V\left(T_{2}(G)\right) \backslash V(G), d_{T_{2}(G)}(x)=2$. Also $\left|V\left(T_{2}(G)\right)\right|=p+q$ and $\left|E\left(T_{2}(G)\right)\right|=3 q$. Hence the hyper Zagreb index of $T_{2}(G)$ is given by,

\section{$H M\left(T_{2}(G)\right)$}

$$
\begin{aligned}
= & \sum_{x y \in E\left(T_{2}(G)\right)}\left(d_{T_{2}(G)}(x)+d_{T_{2}(G)}(y)\right)^{2} \\
= & \sum_{x, y \in V(G), x y \in E\left(T_{2}(G)\right)}\left(d_{T_{2}(G)}(x)+d_{T_{2}(G)}(y)\right)^{2} \\
+ & \sum_{u \in V(G), v \in V\left(T_{2}(G)\right) \backslash V(G), u v \in E\left(T_{2}(G)\right)}\left(d_{T_{2}(G)}(u)+d_{T_{2}(G)}(v)\right)^{2} \\
= & \sum_{x y \in E(G)}\left(2 d_{G}(x)+2 d_{G}(y)\right)^{2}+\sum_{u \in V(G)} d_{G}(u)\left(2 d_{G}(u)+2\right)^{2} \\
= & 4 \sum_{x y \in E(G)}\left(d_{G}(x)+d_{G}(y)\right)^{2} \\
+ & \sum_{u \in V(G)}\left(4 d_{G}^{3}(u)+8 d_{G}^{2}(u)+4 d_{G}(u)\right) \\
= & 4 H M(G)+4 F(G)+8 M_{1}(G)+8 q .
\end{aligned}
$$

\section{Theorem 1.1}

Let $G$ be a connected graph on $p$ vertices and $q$ edges. Then $H M\left(T_{1}(G)\right)=E M_{3}(G)+2 E M_{2}(G)+8 E M_{1}(G)+H M(G)+$ $8 M_{1}(G)-16 q$.

Proof. From the structure of the edge-semitotal graph $T_{1}(G)$, it is clear that $d_{T_{1}(G)}(v)=d_{G}(v), d_{T_{1}(G)}(e)=d_{G}(u)+d_{G}(v)$ where $e=u v$ in $T_{1}(G)$. The edges of the graph $T_{1}(G)$ is $\frac{M_{1}(G)}{2}+m$. Hence the hyper zagreb index of $T_{1}(G)$ is given by,

$$
\begin{aligned}
& H M\left(T_{1}(G)\right)=\sum_{u v \in E\left(T_{1}(G)\right)}\left(d_{T_{1}(G)}(u)+d_{T_{1}(G)}(v)\right)^{2} \\
= & \sum_{u v \in E\left(T_{1}(G)\right) \cap E(L(G))}\left(d_{T_{1}(G)}(u)+d_{T_{1}(G)}(v)\right)^{2} \\
& +\sum_{u v \in E\left(T_{1}(G)\right)-E(L(G))}\left(d_{T_{1}(G)}(u)+d_{T_{1}(G)}(v)\right)^{2} \\
= & \sum_{u=a b, v=b c \in E(G)}\left(\left(d_{G}(a)+2 d_{G}(b)+d_{G}(c)\right)^{2}\right. \\
& +\sum_{u w \in 2 E(G)}\left(\left(d_{G}(u)+d_{G}(u)+d_{G}(w)\right)^{2}\right. \\
= & \sum_{e_{i}-e_{j} \in E(G)}\left(d_{G}\left(e_{i}\right)+d_{G}\left(e_{j}\right)+2\right)^{2} \\
& +\sum_{u w \in E(G)}\left(\left(d_{G}(u)+d_{G}(w)+d_{G}(u)+d_{G}(w)\right)^{2}\right. \\
= & \sum_{e_{i}-e_{j} \in E(G)}\left[\left(d_{G}\left(e_{i}\right)+d_{G}\left(e_{j}\right)\right)^{2}+8\left(d_{G}\left(e_{i}\right)+d_{G}\left(e_{j}\right)\right)+16\right] \\
& +4 \sum_{u w \in E(G)}\left(d_{G}(u)+d_{G}(w)\right)^{2} \\
= & E M_{3}(G)+2 E M_{2}(G)+8 E M_{1}(G)+H M(G)+8 M_{1}(G)-16 q .
\end{aligned}
$$

\section{Theorem 1.2}

Let $G$ be a connected graph on $p$ vertices and $q$ edges. Then $H M(T(G))=E M_{3}(G)+2 E M_{2}(G)+8 E M_{1}(G)+H M(G)+$ $8 M_{1}(G)-16 q$.

Proof. From the structure of the total graph $T(G)$, it is observe that, for the edge $e=u v$ in $T(G), d_{T(G)}(v)=2 d_{G}(v), d_{T(G)}(e)=$ $d_{G}(u)+d_{G}(v)$. The edges of the graph $T(G)$ is $\frac{M_{1}(G)}{2}+2 m$. Hence the hyper zagreb index of $T(G)$ is given by,

$$
\begin{aligned}
& H M(T(G))=\sum_{u v \in E(T(G))}\left(d_{T(G)}(u)+d_{T(G)}(v)\right)^{2} \\
= & \sum_{u v \in E(T(G)) \cap(E(G))}\left(d_{T(G)}(u)+d_{T(G)}(v)\right)^{2} \\
& +\sum_{u v \in E(T(G)) \cap E(L(G))}\left(d_{T(G)}(u)+d_{T(G)}(v)\right)^{2} \\
& +\sum_{u v \in E(T(G))-(E(G) \cup E(L(G)))}\left(d_{T(G)}(u)+d_{T(G)}(v)\right)^{2} \\
= & \sum_{u=a b, v=b c \in E(G)}\left(\left(d_{G}(a)+2 d_{G}(b)+d_{G}(c)\right)^{2}\right. \\
& +\sum_{u w \in 2 E(G)}\left(\left(d_{G}(u)+d_{G}(u)+d_{G}(w)\right)^{2}\right. \\
= & \sum_{e_{i}-e_{j} \in E(G)}\left(d_{G}\left(e_{i}\right)+d_{G}\left(e_{j}\right)+2\right)^{2} \\
& +\sum_{u w \in E(G)}\left(\left(d_{G}(u)+d_{G}(w)+d_{G}(u)+d_{G}(w)\right)^{2}\right. \\
= & \sum_{e_{i}-e_{j} \in E(G)}\left[\left(d_{G}\left(e_{i}\right)+d_{G}\left(e_{j}\right)\right)^{2}+8\left(d_{G}\left(e_{i}\right)+d_{G}\left(e_{j}\right)\right)+16\right] \\
& +4 \sum_{u w \in E(G)}\left(d_{G}(u)+d_{G}(w)\right)^{2} \\
= & E M_{3}(G)+2 E M_{2}(G)+8 E M_{1}(G)+H M(G)+8 M_{1}(G)-16 q .
\end{aligned}
$$

\section{Theorem 1.3}

Let $G$ be a connected graph on $p$ vertices and $q$ edges. Then $H M(L(G))=8 M_{1}(G)-8 H M_{1}(G)+H M_{2}(G)-16 q$.

Proof. One can see that the vertices and edges of $L(G)$ are $q$ and $\frac{M_{1}(G)}{2}-m$, respectively. Moreover any edge $e=x y$ of the graph $G$ 
is incident to $d_{G}(e)=d_{G}(x)+d_{G}(v)-2$ other edges of $G$. Hence the hyper zagreb index of $L(G)$ is given by,

$$
\begin{aligned}
H M(L(G)) & =\sum_{x y \in E(L(G)}\left(d_{L(G)}(x)+d_{L(G)}(y)\right)^{2} \\
& =\sum_{u v, v w \in E(G)}\left(d_{G}(u)+2 d_{G}(v)+d_{G}(w)-4\right)^{2} \\
& =\sum_{u v, v w \in E(G)}\left(\left(d_{G}(u)+2 d_{G}(v)+d_{G}(w)\right)^{2}\right. \\
& \left.-8\left(d_{G}(u)+2 d_{G}(v)+d_{G}(w)\right)+16\right) \\
& =H M_{2}(G)-8 H M_{1}(G)+16\left(\frac{M_{1}(G)}{2}-q\right) \\
& =8 M_{1}(G)-8 H M_{1}(G)+H M_{2}(G)-16 q .
\end{aligned}
$$

\subsection{Generalized Transformation Graphs}

Sampathkumar and Chikkodimath [23] defined the semitotal-point graph of given graph. Based on this definition, Gutman were introduced some new graphical transformations. These generalize the concept of semitotal-point graph.

Let $G=(V, E)$ be a graph, and let $\alpha, \beta$ be two elements of $V(G) \cup$ $E(G)$. The associativity of $\alpha$ and $\beta$ is defined as + if they are adjacent or incident in $G$, otherwise is - . Let $a b$ be a $2-$ permutation of the set $\{+,-\}$. Let $\alpha$ and $\beta$ correspond to the first term $a$ of $a b$ if both $\alpha$ and $\beta$ are in $V(G)$, whereas $\alpha$ and $\beta$ correspond to the second term $b$ of $a b$ if one of $\alpha$ and $\beta$ is in $V(G)$ and the other is in $E(G)$. The generalized transformation graph $G^{a b}$ of $G$ is defined on the vertex set $V(G) \cup E(G)$. Two vertices $\alpha$ and $\beta$ of $G^{a b}$ are joined by an edge if and only if their associativity in $G$ is consistent with the corresponding term of $a b$.

In view of above, one can obtain four graphical transformations of graphs, since there are four distinct 2-permutations of $\{+-\}$. Note that $G^{++}$is just the semitotal-point graph $T_{2}(G)$ of $G$, whereas the other generalized transformation graphs are $G^{+-}, G^{-+}$and $G^{--}$. In other words, the generalized transformation graph $G^{a b}$ is a graph whose vertex set is $V(G) \cup E(G)$, and $\alpha, \beta \in V\left(G^{a b}\right)$. $\alpha$ and $\beta$ are adjacent in $G^{a b}$ if and only if either $(*)$ or $(* *)$ holds:

$(*) \alpha, \beta \in V(G), \alpha, \beta$ are adjacent in $G$ if $a=+$ and $\alpha, \beta$ are not adjacent in $G$ if $a=-$.

$(* *) \alpha \in V(G)$ and $\beta \in E(G), \alpha, \beta$ are incident in $G$ if $b=+$ and $\alpha, \beta$ are not incident in $G$ if $b=-$.

The vertex $v_{i}$ of $G^{a b}$ corresponding to a vertex $v_{i}$ of $G$ is referred to as a point vertex. The vertex $e_{i}$ of $G^{a b}$ corresponding to an edge $e_{i}$ of $G$ is referred to as a line vertex.

\section{Theorem 1.4}

Let $G$ be a connected graph on $p$ vertices and $q$ edges. Then $H M\left(G^{++}\right)=4 H M(G)+8 q+4 F(G)+8 M_{1}(G)$.

Proof. Note that $\left|V\left(G^{++}\right)\right|=p+q$ and $\left|E\left(G^{++}\right)\right|=2 q$. Moreover, $d_{G^{++}}\left(v_{i}\right)=2 d_{G}\left(v_{i}\right)$ and $d_{G^{++}}\left(e_{i}\right)=2$.

$$
\begin{aligned}
H M\left(G^{++}\right)= & \sum_{u v \in E\left(G^{++}\right)}\left(d_{G^{++}}(u)+d_{G^{++}}(v)\right)^{2} \\
= & \sum_{u v \in E\left(G^{++}\right) \cap E(G)}\left(d_{G^{++}}(u)+d_{G^{++}}(v)\right)^{2} \\
& +\sum_{u v \in E\left(G^{++}\right)-E(G)}\left(d_{G^{++}}(u)+d_{G^{++}}(v)\right)^{2} \\
= & \sum_{u v \in E(G)}\left(2 d_{G}(u)+2 d_{G}(v)\right)^{2} \\
& +\sum_{u v \in E\left(G^{++}\right)-E(G)}\left(2+2 d_{G}(v)\right)^{2} \\
= & 4 H M(G)+\sum\left(4+4 d_{G}^{2}(v)+8 d_{G}(v)\right) \\
= & 4 H M(G)+2 m(4)+4 \sum_{u v \in E\left(G^{++}\right)-E(G)} d_{G}^{2}(v) \\
& +8 \sum d_{G}(v) \quad 4 \quad \sum_{v \in V(G)} d_{G}^{2}(v)+8 \sum_{v \in V(G)} d_{G}^{2}(v) \\
= & 4 H M(G)+8 q+4 F(G)+8 M_{1}(G) .
\end{aligned}
$$

\section{Theorem 1.5}

Let $G$ be a connected graph on $p$ vertices and $q$ edges. Then $H M\left(G^{+-}\right)=4 q^{3}+q(p-2)(p+q-2)^{2}$.

Proof. Note that $\left|V\left(G^{+-}\right)\right|=p+q$ and $\left|E\left(G^{+-}\right)\right|=q(p-1)$. Moreover, $d_{G^{++}}\left(v_{i}\right)=q$ and $d_{G^{++}}\left(e_{i}\right)=p-2$.

$$
\begin{aligned}
H M\left(G^{+-}\right)= & \sum_{u v \in E\left(G^{+-}\right)}\left(d_{G^{+-}}(u)+d_{G^{+-}}(v)\right)^{2} \\
= & \sum_{u v \in E\left(G^{+-}\right) \cap E(G)}\left(d_{G^{+-}}(u)+d_{G^{+-}}(v)\right)^{2} \\
& +\sum_{u v \in E\left(G^{+-}\right)-E(G)}\left(d_{G^{+-}}(u)+d_{G^{+-}}(v)\right)^{2} \\
= & \sum_{u v \in E(G)}(m+m)^{2}+\sum_{u v \in E\left(G^{+-}\right)-E(G)}(q+(p-2))^{2} \\
= & q(2 q)^{2}+(p q-2 q)(p+q-2)^{2} \\
= & 4 q^{3}+q(p-2)(p+q-2)^{2} .
\end{aligned}
$$

Theorem 1.6 Let $G$ be a connected graph on $p$ vertices and $q$ edges. Then $H M\left(G^{-+}\right)=2(p-1)^{2}[p(p-1)+q]$.

Proof.Note that $\left|V\left(G^{-+}\right)\right|=p+q$ and $\left|E\left(G^{-+}\right)\right|=q+\frac{p(p-1)}{2}$. Moreover, $d_{G^{-+}}\left(v_{i}\right)=p-1$ and $d_{G^{++}}\left(e_{i}\right)=2$.

$$
\begin{aligned}
H M\left(G^{-+}\right)= & \sum_{u v \in E\left(G^{-+}\right)}\left(d_{G^{-+}}(u)+d_{G^{-+}}(v)\right)^{2} \\
= & \sum_{u v \in E\left(G^{-+}\right)}\left(d_{G^{-+}}(u)+d_{G^{-+}}(v)\right)^{2} \\
& +\sum_{u v \in E\left(G^{-+}\right) \cup E(\bar{G})}\left(d_{G^{-+}}(u)+d_{G^{-+}}(v)\right)^{2} \\
= & \sum_{u v \in E(\bar{G})}\left((p-1)+\left(p_{1}\right)\right)^{2}+\sum_{u v \in E\left(G^{-+}\right)-E(\bar{G})}(2+(p-1))^{2} \\
= & \left(\left(\begin{array}{l}
p \\
2
\end{array}\right)-q\right) 4(p-1)^{2}+\left(\left(\begin{array}{c}
p \\
2
\end{array}\right)+q-\left(\begin{array}{c}
p \\
2
\end{array}\right)+q\right)(p+1)^{2} \\
= & 2(p-1)^{2}[p(p-1)+q] .
\end{aligned}
$$

Theorem 1.7 Let $G$ be a connected graph on $p$ vertices and $q$ edges. Then $H M\left(G^{--}\right)=(2 p+2 q-2)^{2}\left(\left(\begin{array}{l}p \\ 2\end{array}\right)-q\right)+4 \overline{H M}(G)-$ $4(2 p+2 q-2) \overline{M_{1}}(G)(2 p+q-3)^{2} q(p-2)-2(2 p+q-3)\left(2 m^{2}-\right.$ $\left.M_{1}(G)\right)+4 \sum_{u v \in E\left(G^{--}\right)-E(\bar{G})} d_{G}^{2}(v)$.

Proof. Note that $\left|V\left(G^{--}\right)\right|=p+q$ and $\left|E\left(G^{--}\right)\right|=\frac{p(p-1)}{2}+$ $q(p-3)$. Moreover, $d_{G^{--}}\left(v_{i}\right)=p+q-1-2 d_{G}\left(v_{i}\right)$ and $d_{G^{--}}\left(e_{i}\right)=$ $p-2$. 


$$
\begin{aligned}
H M\left(G^{--}\right) & \\
= & \sum_{u v \in E\left(G^{--}\right)}\left(d_{G^{--}}(u)+d_{G^{--}}(v)\right)^{2} \\
= & \sum_{u v \in E\left(G^{--}\right) \cap E(\bar{G})}\left(d_{G^{--}}(u)+d_{G^{--}}(v)\right)^{2} \\
& +\sum_{u v \in E\left(G^{--}\right)-E(\bar{G})}\left(d_{G^{--}}(u)+d_{G^{--}}(v)\right)^{2} \\
= & \sum_{u v \in E(\bar{G})}\left(p+q+1-2 d_{G}(u)+p+q-1-2 d_{G}(v)\right)^{2} \\
& +\sum_{u v \in E\left(G^{--}\right)-E(\bar{G})}\left((p-2)+\left(p+q-1-2 d_{G}(v)\right)\right)^{2} \\
= & \sum_{u v \in E(\bar{G})}\left[(2 p+2 q-2)^{2}+4\left(d_{G}(u)+d_{G}(v)\right)^{2}\right. \\
& \left.-4(2 p+2 q-2)\left(d_{G}(u)+d_{G}(v)\right)\right] \\
& +\sum_{u v \in E\left(G^{--}\right)-E(\bar{G})}\left[(2 p+q-3)^{2}+4 d_{G}^{2}(v)\right. \\
& \left.-4(2 p+q-3) d_{G}(v)\right] \\
= & (2 p+2 q-2)^{2}\left(\left(\begin{array}{l}
p \\
2
\end{array}\right)-q\right)+4 \overline{H M}(G)-4(2 p+2 q-2) \overline{M_{1}}(G) \\
& (2 p+q-3)^{2} q(p-2)-2(2 p+q-3)\left(2 m^{2}-M_{1}(G)\right) \\
& +4 \sum_{u v \in E\left(G^{--}\right)-E(\bar{G})} d_{G}^{2}(v) . \\
&
\end{aligned}
$$

\subsection{Thorn Graph}

An edge $e=u v$ of a graph $G$ is called a thorn if either $d_{G}(u)=1$ or $d_{G}(v)=1$. The concept of thorn graph was first introduced by Gutman [17] by joining a number of thorn to each vertex of any given graph $G$. Some of the topological indices of thorn graphs are studied in $[18,20,21]$.

Let $V(G)$ and $V\left(G^{T}\right)$ be the vertex sets of $G$ and its thorn graph $G^{T}$ respectively. Let $V(G)=\left\{v_{1}, v_{2}, \ldots, v_{n}\right\}$ and $V^{T}(G)=V(G) \cup V_{1} \cup$ $V_{2} \cup \ldots \cup V_{n}$, where $V_{i}$ are the set of degree one vertices attached to the vertices $v_{i}$ in $G^{T}$ and $V i \cup V_{j}=\varphi, i \neq j$. Let the vertices of the set $V_{i}$ are denoted by $v_{i j}$ for $j=1,2, \ldots, p_{i}$ and $i=1,2, \ldots, n$. Thus $\left|V\left(G^{T}\right)\right|=n+z$ where, $z=\sum_{i=1}^{n} p_{i}$. Then the degree of the vertices $v_{i}$ in $G^{T}$ are given by $d_{G^{T}}\left(v_{i}\right)=d_{G}\left(v_{i}\right)+p_{i}$, for $i=1,2, \ldots, n$.

The hyper Zagreb index of thorn graph is computed as follows.

\section{Theorem 1.8}

Let $G$ be a graph. Then $H M\left(G^{T}\right)=H M(G)+2 \sum_{v_{i} v_{j} \in E(G)}\left(p_{i}+\right.$ $\left.p_{j}\right)\left(d_{G}\left(v_{i}\right)+d_{G}\left(v_{j}\right)\right)+\sum_{v_{i} v_{j} \in E(G)}\left(p_{i}+p_{j}\right)^{2}+\sum_{i=1}^{n} p_{i} d_{G}^{2}\left(v_{i}\right)+$ $\sum_{i=1}^{n} p_{i}\left(p_{i}+1\right)^{2}+2 \sum_{i=1}^{n} p_{i}\left(p_{i}+1\right) d_{G}\left(v_{i}\right)$.

Proof. From the definition of hyper Zagreb index,

$$
\begin{aligned}
H M\left(G^{T}\right)= & \sum_{v_{i} v_{j} \in E\left(G^{T}\right)}\left(d_{G^{T}}\left(v_{i}\right)+d_{G^{T}}\left(v_{j}\right)\right)^{2} \\
= & \sum_{v_{i} v_{j} \in E(G)}\left(d_{G^{T}}\left(v_{i}\right)+d_{G^{T}}\left(v_{j}\right)\right)^{2} \\
& +\sum_{i=1}^{n} \sum_{j=1}^{p_{i}}\left(d_{G^{T}}\left(v_{i}\right)+d_{G^{T}}\left(v_{i j}\right)\right)^{2} \\
= & \sum_{v_{i} v_{j} \in E(G)}\left(d_{G}\left(v_{i}\right)+p_{i}+d_{G}\left(v_{j}\right)+p_{j}\right)^{2} \\
& +\sum_{i=1}^{n} \sum_{j=1}^{p_{i}}\left(d_{G}\left(v_{i}\right)+p_{i}+1\right)^{2} .
\end{aligned}
$$

$$
\text { Let } \begin{aligned}
S_{1}= & \sum_{v_{i} v_{j} \in E(G)}\left(d_{G}\left(v_{i}\right)+p_{i}+d_{G}\left(v_{j}\right)+p_{j}\right)^{2} \\
= & \sum_{v_{i} v_{j} \in E(G)}\left(\left(d_{G}\left(v_{i}\right)+d_{G}\left(v_{j}\right)\right)^{2}\right. \\
& +2\left(p_{i}+p_{j}\right)\left(d_{G}\left(v_{i}\right)+d_{G}\left(v_{j}\right)\right)+\left(p_{i}+p_{j}\right)^{2} \\
= & H M(G)+2 \sum_{v_{i} v_{j} \in E(G)}\left(p_{i}+p_{j}\right)\left(d_{G}\left(v_{i}\right)+d_{G}\left(v_{j}\right)\right) \\
& +\sum_{v_{i} v_{j} \in E(G)}\left(p_{i}+p_{j}\right)^{2} .
\end{aligned}
$$

$$
\text { Let } \begin{aligned}
S_{2} & =\sum_{i=1}^{n} \sum_{j=1}^{p_{i}}\left(d_{G}\left(v_{i}\right)+p_{i}+1\right)^{2} \\
& =\sum_{i=1}^{n} \sum_{j=1}^{p_{i}}\left(d_{G}^{2}\left(v_{i}\right)+\left(p_{i}+1\right)^{2}+2\left(p_{i}+1\right) d_{G}\left(v_{i}\right)\right) \\
& =\sum_{i=1}^{n} p_{i} d_{G}^{2}\left(v_{i}\right)+\sum_{i=1}^{n} p_{i}\left(p_{i}+1\right)^{2}+2 \sum_{i=1}^{n} p_{i}\left(p_{i}+1\right) d_{G}\left(v_{i}\right) .
\end{aligned}
$$

The desired result is obtained by add $S_{1}$ and $S_{2}$.

Corollary 1.1 If $G^{T}$ is a thorn graph with parameters $p_{i}=t$ for all $i$, then $H M\left(G^{T}\right)=H M(G)+5 t M_{1}(G)+n t(t+1)^{2}+4 t m(2 t+1)$.

Corollary 1.2 If the parameters $p_{i}(i \geq 1)$ is equal to the degree of the corresponding vertex $v_{i}$, then $H M\left(G^{T}\right)=4 H M(G)+4 M_{1}(G)+$ $4 F(G)+2 m$.

Corollary 1.3 If $\mu$ is a integer and $\mu>d_{G}\left(v_{i}\right), i=1,2, \ldots, n$ and if $G^{T}$ is a thorn graph with parameters $p_{i}=\mu-d_{G}\left(v_{i}\right)$, then $H M\left(G^{T}\right)=\left(2 \mu^{2}+1\right) M_{1}(G)-F(G)-\left(\mu^{2}+4 \mu+1\right) m+\mu(\mu+$ $1)^{2} n$.

Corollary 1.4 If the number of thorns, that is pendant edges attached to any vertex of the parent graph is a linear function of the degree of the corresponding vertex $v_{i}$, that is $p_{i}=a d_{G}\left(v_{i}\right)+b$, where $a$ and $b$ are any constants, then $H M\left(G^{T}\right)=(a+1)^{2} H M(G)+$ $\left(a^{2}(3 b+4)+2 a(2 b+1)+7 b\right) M_{1}(G)+\left(a^{3}+3 a\right) F(G)+b^{2}(n b+$ $2 n+6 a m+24)+2 m(a+2 b+6 a b)+n b$.

\subsection{Subdivision Vertex Corona of Graphs}

Let $G_{1}$ and $G_{2}$ be any two simple connected graph with $n_{1}$ and $n_{2}$ number of vertices and $m_{1}$ and $m_{2}$ number of edges respectively. The subdivision vertex corona of $G_{1}$ and $G_{2}$ is denoted by $G_{1} \circ G_{2}$ and was introduced by Lu and Miao [19]. The graph $G_{1} \circ G_{2}$ is obtained from $S\left(G_{1}\right)$ and $n_{1}$ copies of $G_{2}$, by joining the $i$-th vertex of $V\left(G_{1}\right)$ to every vertex in the $i$-th copy of $G_{2}$. Let $V\left(G_{1}\right)=\left\{v_{1}, v_{2}, \ldots, v_{n_{1}}\right\}, I\left(G_{1}\right)=\left\{v_{1}^{e}, v_{2}^{e}, \ldots, v_{m_{1}}^{e}\right\}$ and $V\left(G_{2}\right)=$ $\left\{u_{1}, u_{2}, \ldots, u_{n_{2}}\right\}$, so that $V(S(G))=V(G) \cup I(G)$. Let $u_{1}^{i}, u_{2}^{i}, \ldots, u_{n_{2}}^{i}$ denote the vertices of the $i$-th copy of $G_{2, i} i=1,2, \ldots, n_{1}$, so that $V\left(G_{1} \circ G_{2}\right)=V\left(G_{1}\right) \cup I\left(G_{1}\right) \cup\left[V\left(G_{2,1}\right) \cup V\left(G_{2,2}\right) \cup \ldots \cup V\left(G_{2, n_{1}}\right)\right]$. The hyper Zagreb index of Subdivision Vertex Corona of Graphs is computed as follows.

Theorem 1.9 Let $G_{1}$ and $G_{2}$ be two graph with $n_{1}, n_{2}$ and $m_{1}, m_{2}$ edges, respectively. Then $H M\left(G_{1} \circ G_{2}\right)=$ $n_{1} H M\left(G_{2}\right)+5 n_{1} M_{1}\left(G_{2}\right)+\left(3 n_{1}+4\right) M_{1}\left(G_{1}\right)+4 n_{1} m_{2}+2\left(n_{2}+\right.$ $2)^{2} m_{1}+n_{1} n_{2}\left(n_{2}+1\right)^{2}+8 m_{1} m_{2}+4\left(n_{2}+1\right)\left(n_{2} m_{1}+n_{1} m_{2}\right)$.

Proof. The degree of the vertices of $G_{1} \circ G_{2}$ is given by $d_{G_{1} \circ G_{2}}\left(v_{i}\right)=d_{G_{1}}\left(v_{i}\right)+n_{2}$ for $i=1,2, \ldots, n_{1}, d_{G_{1} \circ G_{2}}\left(e_{i}\right)=2$ for $i=1,2, \ldots, m_{1}, d_{G_{1} \circ G_{2}}\left(u_{j}^{i}\right)=d_{G_{2}}\left(u_{j}\right)+1$ for $i=1,2, \ldots, n_{1}$ and $j=1,2, \ldots, n_{2}$. Let the vertex set of $G_{1} \circ G_{2}$ can be partitioned into three subsets $E_{1}=\left\{x y \in E\left(G_{1} \circ G_{2}\right) \mid x, y \in V\left(G_{2, i}\right), i=1,2, \ldots, n_{1}\right\}$, $E_{2}=\left\{x y \in E\left(G_{1} \circ G_{2}\right) \mid x \in V\left(G_{1}\right), y \in I\left(G_{1}\right)\right\}$, and $E_{3}=\{x y \in$ 


$$
\begin{aligned}
& \left.E\left(G_{1} \circ G_{2}\right) \mid x \in V\left(G_{1}\right), y \in V\left(G_{2, i}\right), i=1,2, \ldots, n_{1}\right\} . \\
& S_{1}=\sum_{x y \in E_{1}}\left(d_{G_{1} \circ G_{2}}(x)+d_{G_{1} \circ G_{2}}(y)\right)^{2} \\
& =\sum_{i=1}^{n_{1}} \sum_{u_{i} u_{j} \in E\left(G_{2}\right)}\left(d_{G_{2}}\left(u_{i}\right)+1+d_{G_{2}}\left(u_{j}\right)+1\right)^{2} \\
& =\sum_{i=1}^{n_{1}} \sum_{u_{i} u_{j} \in E\left(G_{2}\right)}\left(\left(d_{G_{2}}\left(u_{i}\right)+d_{G_{2}}\left(u_{j}\right)\right)^{2}\right. \\
& \left.+4\left(d_{G_{2}}\left(u_{i}\right)+d_{G_{2}}\left(u_{j}\right)\right)+4\right) \\
& =n_{1} H M\left(G_{2}\right)+4 n_{1} M_{1}\left(G_{2}\right)+4 n_{1} m_{2} \text {. } \\
& S_{2}=\sum_{x y \in E_{2}}\left(d_{G_{1} \circ G_{2}}(x)+d_{G_{1} \circ G_{2}}(y)\right)^{2} \\
& =\sum_{i=1}^{n_{1}}\left(d_{G_{1}}\left(v_{i}\right)+n_{2}+2\right) d_{G}\left(v_{i}\right) \\
& =\sum_{i=1}^{n_{1}}\left(d_{G_{1}}^{2}\left(v_{i}\right)+\left(n_{2}+2\right)^{2}+2\left(n_{2}+2\right) d_{G_{1}}\left(v_{i}\right)\right) d_{G_{1}}\left(v_{i}\right) \\
& =F\left(G_{1}\right)+2\left(n_{2}+2\right)^{2} m_{1}+2\left(n_{2}+2\right) M_{1}\left(G_{1}\right) \text {. } \\
& S_{3}=\sum_{x y \in E_{3}}\left(d_{G_{1} \circ G_{2}}(x)+d_{G_{1} \circ G_{2}}(y)\right)^{2} \\
& =\sum_{i=1}^{n_{1}} \sum_{j=1}^{n_{2}}\left(d_{G_{1}}\left(v_{i}\right)+n_{2}+d_{G_{2}}\left(u_{j}\right)+1\right)^{2} \\
& =\sum_{i=1}^{n_{1}} \sum_{j=1}^{n_{2}}\left(\left(d_{G_{1}}^{2}\left(v_{i}\right)+d_{G_{2}}^{2}\left(u_{j}\right)+\left(n_{2}+1\right)^{2}+2 d_{G_{1}}^{2}\left(v_{i}\right) d_{G_{2}}^{2}\left(u_{j}\right)\right.\right. \\
& \left.+2\left(n_{2}+1\right) d_{G_{1}}^{2}\left(v_{i}\right)+2\left(n_{2}+1\right) d_{G_{2}}^{2}\left(u_{j}\right)\right) \\
& =n_{2} M_{1}\left(G_{1}\right)+n_{1} M_{1}\left(G_{2}\right)+n_{1} n_{2}\left(n_{2}+1\right)^{2}+8 m_{1} m_{2} \\
& +4 n_{2}\left(n_{2}+1\right) m_{1}+4 n_{1}\left(n_{2}+1\right) m_{2} \text {. }
\end{aligned}
$$

Add $S_{1}$ to $S_{3}$ the desired result is obtained.

\subsection{Double Graph and Extended Double Cover}

Let us denote the double graph of a graph $\mathrm{G}$ by $G^{*}$, which is constructed from two copies of $\mathrm{G}$ in the following manner [15,16]. Let $G$ be a graph with $V(G)=\left\{v_{1}, v_{2}, \ldots, v_{n}\right\}$. The vertices of the double graph $G^{*}$ are given by the two sets $X=\left\{x_{1}, x_{2}, \ldots, x_{n}\right\}$ and $Y=\left\{y_{1}, y_{2}, \ldots, y_{n}\right\}$. Thus for each vertex $v_{i} \in V(G)$, there are two vertices $x_{i}$ and $y_{i}$ in $V\left(G^{*}\right)$. The double graph $G^{*}$ includes the initial edge set of each copies of $G$, and for any edge $v_{i} v_{j} \in E(G)$, two more edges $x_{i} y_{j}$ and $x_{j} y_{i}$ are added.

\section{Theorem 1.10}

The hyper Zagreb index of the double graph $G^{*}$ of a graph $G$ is given by $H M\left(G^{*}\right)=16 H M(G)$.

Proof. From the definition of double graph it is clear that $d_{G^{*}}\left(x_{i}\right)=$ $d_{G^{*}}\left(y_{i}\right)=2 d_{G}\left(v_{i}\right)$, where $v_{i} \in V(G)$ and $x_{i}, y_{i} \in V\left(G^{*}\right)$ are corresponding clone vertices of $v_{i}$. Therefore $H M\left(G^{*}\right)$

$$
\begin{aligned}
= & \sum_{u v \in E\left(G^{*}\right)}\left(d_{G^{*}}(u)+d_{G^{*}}(v)\right)^{2} \\
= & \sum_{x_{i} x_{j} \in E\left(G^{*}\right)}\left(d_{G^{*}}\left(x_{i}\right)+d_{G^{*}}\left(x_{j}\right)\right)^{2}+\sum_{y_{i} y_{j} \in E\left(G^{*}\right)}\left(d_{G^{*}}\left(y_{i}\right)+d_{G^{*}}\left(y_{j}\right)\right)^{2} \\
& +\sum_{x_{i} y_{j} \in E\left(G^{*}\right)}\left(d_{G^{*}}\left(x_{i}\right)+d_{G^{*}}\left(y_{j}\right)\right)^{2} \\
& +\sum_{x_{j} y_{i} \in E\left(G^{*}\right)}\left(d_{G^{*}}\left(x_{j}\right)+d_{G^{*}}\left(y_{i}\right)\right)^{2} \\
= & 4 \sum_{v_{i} v_{j} \in E(G)}\left(2 d_{G}\left(v_{i}\right)+2 d_{G}\left(v_{j}\right)\right)^{2} \\
= & 16 H M(G) .
\end{aligned}
$$

The construction of the entended double cover was introduced by Alon[16] in 1986. Let $G$ be a simple connected graph with $V(G)=$ $\left\{v_{1}, v_{2}, \ldots, v_{n}\right\}$. The extended double cover of $G$, denoted by $G^{* *}$ is the bipartite graph with bipartition $(X, Y)$ where $X=\left\{x_{1}, x_{2}, \ldots, x_{n}\right\}$ and $Y=\left\{y_{1}, y_{2}, \ldots, y_{n}\right\}$ in which $x_{i}$ and $y_{j}$ are adjacent if and only if either $v_{i}$ and $v_{j}$ are adjacent in $G$ or $i=j$.

\section{Theorem 1.11}

Let $G$ be a graph with $n$ vertices and $m$ edges. Then the hyper Zagreb index of the extended double cover $G^{* *}$ of the graph $G$ is given by $H M\left(G^{* *}\right)=2 H M(G)+8 M_{1}(G)+8 m$.

Proof. From the definition of extended double cover graph $G^{* *}$ consists of $2 n$ vertices and $n+2 m$ edges. Moreover, $d_{G^{* *}}\left(x_{i}\right)=$ $d_{G^{* *}}\left(y_{i}\right)=d_{G}\left(v_{i}\right)+1$, for $i=1,2, \ldots, n$. Here, $v_{i} \in V(G)$ and $x_{i}, y_{i} \in V\left(G^{* *}\right)$ are corresponding clone vertices of $v_{i}$. Hence the hyper Zagreb index of $G^{* *}$ is given by,

$$
\begin{aligned}
H M\left(G^{* *}\right)= & \sum_{u v \in E\left(G^{* *}\right)}\left(d_{G^{* *}}(u)+d_{G^{* *}}(v)\right)^{2} \\
= & \sum_{x_{i} y_{j} \in E\left(G^{* *}\right)}\left(d_{G^{* *}}\left(x_{i}\right)+d_{G^{* *}}\left(y_{j}\right)\right)^{2} \\
& +\sum_{x_{j} y_{i} \in E\left(G^{* *}\right)}\left(d_{G^{* *}}\left(x_{j}\right)+d_{G^{* *}}\left(y_{i}\right)\right)^{2} \\
& +\sum_{i=1}^{n}\left(d_{G^{* *}}\left(x_{i}\right)+d_{G^{* *}}\left(y_{i}\right)\right)^{2} \\
= & 2 \sum_{v_{i} v_{j} \in E(G)}\left(d_{G}\left(v_{i}\right)+1+d_{G}\left(v_{j}\right)+1\right)^{2} \\
= & 2 \sum_{v_{i} v_{j} \in E(G)}\left(\left(d_{G}\left(v_{i}\right)+d_{G}\left(v_{j}\right)\right)^{2}+4\left(d_{G}\left(v_{i}\right)+d_{G}\left(v_{j}\right)\right)+4\right) \\
= & 2 H M(G)+8 M_{1}(G)+8 m .
\end{aligned}
$$

\subsection{Splice and Link Graphs}

A splice of $G_{1}$ and $G_{2}$ was introduced by Doslic[22]. Let $y \in v\left(G_{1}\right)$ and $z \in v\left(G_{2}\right)$ be two given vertices of $G_{1}$ and $G_{2}$ at the vertices $\mathrm{y}$ and $\mathrm{z}$ is denoted by $S\left(G_{1}, G_{2}\right)(y, z)$ and is obtained by identifying the vertices $\mathrm{y}$ and $\mathrm{z}$ in the union of $G_{1}$ and $G_{2}$. The vertex set of $S\left(G_{1}, G_{2} ; y, z\right)$ is given by $V\left(S\left(G_{1}, G_{2} ; y, z\right)\right)=\left[V\left(G_{1}\right)-y\right] \cup$ $\left[V\left(G_{2}\right)-z\right] \cup x$, where the vertex obtained by identifying $y$ and $z$ by $x$. Let $N(v)$ denotes the set of vertices which are the neighbors of the vertex $v$, so that $|N(v)|=d_{G}(v)$. Also, let $\delta_{G}(v)=\sum_{u \in N(v)} d_{G}(u)$.

\section{Theorem 1.12}

The hyper Zagreb index of the splice graph $S\left(G_{1}, G_{2} ; y, z\right)$ of the graph $G_{1}$ and $G_{2}$ is given by $\operatorname{HM}\left(S\left(G_{1}, G_{2} ; y, z\right)\right)=$ $H M\left(G_{1}\right)+H M\left(G_{2}\right)+d_{G_{1}}^{2}(y) d_{G_{2}}(z)+d_{G_{1}}(y) d_{G_{2}}^{2}(z)+$ $2 d_{G_{2}}(z)\left(d_{G_{1}}^{2}(y)+\delta_{G_{1}}(y)\right)+2 d_{G_{1}}(y)\left(d_{G_{2}}^{2}(z)+\delta_{G_{1}}(z)\right)$.

Proof. Let $S=S\left(G_{1}, G_{2} ; y, z\right)$. From the construction of the splice of two graphs it is clear that $d_{S}(v)=$ $\left\{\begin{array}{l}d_{G_{i}}(v), \text { if } v \in V\left(G_{i}\right) \text { and } v \neq y, z \\ d_{G_{1}}(y)+d_{G_{2}}(z) \text { if } v=y, z\end{array}\right.$

Hence the hyper Zagreb index of the splice graph $S$ is given by,

$$
\begin{aligned}
H M(S)= & \sum_{u v \in E(S)}\left(d_{S}(u)+d_{S}(v)\right)^{2} \\
= & \sum_{u v \in E\left(G_{1}\right) u v \neq y}\left(d_{G_{1}}(u)+d_{G_{1}}(v)\right)^{2} \\
& +\sum_{u v \in E\left(G_{2}\right) u v \neq z}\left(d_{G_{2}}(u)+d_{G_{2}}(v)\right)^{2} \\
& +\sum_{u v \in E\left(G_{1}\right), u=y, v \in V\left(G_{1}\right)}\left(d_{G_{1}}(y)+d_{G_{2}}(z)+d_{G_{1}}(v)\right)^{2} \\
& +\sum_{u v \in E\left(G_{2}\right), u=z, v \in V\left(G_{2}\right)}\left(d_{G_{1}}(y)+d_{G_{2}}(z)+d_{G_{2}}(v)\right)^{2}
\end{aligned}
$$




$$
\begin{aligned}
& =\sum_{u v \in E\left(G_{1}\right) u v \neq y}\left(d_{G_{1}}(u)+d_{G_{1}}(v)\right)^{2} \\
& +\sum_{u v \in E\left(G_{2}\right) u v \neq z}\left(d_{G_{2}}(u)+d_{G_{2}}(v)\right)^{2} \\
& +\sum_{u v \in E\left(G_{1}\right), u=y, v \in V\left(G_{1}\right)}\left(d_{G_{1}}(y)+d_{G_{1}}(v)\right)^{2} \\
& \quad+\sum_{u v \in E\left(G_{2}\right), u=z, v \in V\left(G_{2}\right)}\left(d_{G_{2}}(z)+d_{G_{2}}(v)\right)^{2} \\
& \quad+\sum_{u v \in E\left(G_{1}\right), u=y, v \in V\left(G_{2}\right)}\left(d_{G_{2}}(z)\right)^{2} \\
& \quad+\sum_{u v \in E\left(G_{2}\right), u=z, v \in V\left(G_{2}\right)}\left(d_{G_{1}}(y)\right)^{2} \\
& +\sum_{u v \in E\left(G_{1}\right), u=y, v \in V\left(G_{1}\right)} 2 d_{G_{2}}(z)\left(d_{G_{1}}(y)+d_{G_{1}}(v)\right)^{2} \\
& +\sum_{u v \in E\left(G_{2}\right), u=z, v \in V\left(G_{2}\right)} 2 d_{G_{1}}(y)\left(\left(d_{G_{2}}(z)+d_{G_{2}}(v)\right)\right) \\
& \quad H M\left(G_{1}\right)+H M\left(G_{2}\right)+d_{G_{1}}^{2}(y) d_{G_{2}}(z)+d_{G_{1}}(y) d_{G_{2}}^{2}(z) \\
& +2 d_{G_{2}}(z)\left(d_{G_{1}}^{2}(y)+\delta_{G_{1}}(y)\right)+2 d_{G_{1}}(y)\left(d_{G_{2}}^{2}(z)+\delta_{G_{1}}(z)\right) .
\end{aligned}
$$

Theorem 1.13 The hyper Zagreb index of the link graph $L\left(G_{1} \sim\right.$ $\left.G_{2}\right)(y, z)$ of the graph $G_{1}$ and $G_{2}$ is given by $H M\left(G_{1}\right)+$ $H M\left(G_{2}\right)+2 d_{G_{1}}^{2}(y)+2 \delta_{G_{1}}(y)+2 d_{G_{2}}^{2}(z)+2 \delta_{G_{2}}(z)+d_{G_{1}}(y)+$ $d_{G_{2}}(z)+\left(d_{G_{1}}(y)+d_{G_{2}}^{2}(z)\right)$.

Proof. Let $L=L\left(G_{1} \sim G_{2}\right)(y, z)$. From the construction of link graphs, it is clear that

$d_{L}(v)=\left\{\begin{array}{l}d_{G_{i}}(v) v \in V\left(G_{i}\right), i=1,2, \text { if } v \neq y, z \\ d_{G_{i}}(x)+1, \text { if } v=y, z, i=1,2\end{array}\right.$

Hence the hyper Zagreb index of the link graph $L$ is given by,

$$
\begin{aligned}
& H M(L)=\sum_{u v \in E(L)}\left(d_{L}(u)+d_{L}(v)\right)^{2} \\
& =\sum_{u v \in E\left(G_{1}\right)}\left(d_{G_{1}}(u)+d_{G_{1}}(v)\right)^{2} \\
& +\sum_{u v \in E\left(G_{2}\right)}\left(d_{G_{2}}(u)+d_{G_{2}}(v)\right)^{2} \\
& +\sum_{u v \in E\left(G_{1}\right), u=y, v \in V\left(G_{1}\right)}\left(1+d_{G_{1}}(y)+d_{G_{1}}(v)\right)^{2} \\
& =\sum_{u v \in E\left(G_{1}\right)}\left(d_{G_{1}}(u)+d_{G_{1}}(v)\right)^{2} \\
& +\sum_{u v \in E\left(G_{2}\right)}\left(d_{G_{2}}(u)+d_{G_{2}}(v)\right)^{2} \\
& +\sum_{u v \in E\left(G_{1}\right), u=y, v \in V\left(G_{1}\right)}\left(1+d_{G_{1}}(y)+d_{G_{1}}(v)\right)^{2} \\
& +\sum_{u v \in E\left(G_{2}\right), u=z, v \in V\left(G_{2}\right)}\left(1+d_{G_{2}}(z)+d_{G_{2}}(v)\right)^{2} \\
& +\left(\left(d_{G_{1}}(y)+1\right)+\left(d_{G_{2}}(z)+1\right)\right)^{2} \\
& =\sum_{u v \in E\left(G_{1}\right)}\left(d_{G_{1}}(u)+d_{G_{1}}(v)\right)^{2}+\sum_{u v \in E\left(G_{2}\right)}\left(d_{G_{2}}(u)+d_{G_{2}}(v)\right)^{2} \\
& +2 \sum_{u v \in E\left(G_{1}\right), u=y, v \in V\left(G_{1}\right)}\left(d_{G_{1}}(u)+d_{G_{1}}(v)\right)^{2} \\
& +2 \sum_{u v \in E\left(G_{2}\right), u=z, v \in V\left(G_{2}\right)}\left(d_{G_{2}}(u)+d_{G_{2}}(v)\right)^{2} \\
& +2 \sum_{u v \in E\left(G_{1}\right), u=y, v \in V\left(G_{1}\right)} 1+\sum_{u v \in E\left(G_{2}\right), u=z, v \in V\left(G_{2}\right)} 1 \\
& +\left(d_{G_{2}}(y)+d_{G_{2}}(z)+2\right)^{2} \\
& =H M\left(G_{1}\right)+H M\left(G_{2}\right)+2 d_{G_{1}}^{2}(y)+2 \delta_{G_{1}}(y)+2 d_{G_{2}}^{2}(z) \\
& +2 \delta_{G_{2}}(z)+d_{G_{1}}(y)+d_{G_{2}}(z)+\left(d_{G_{1}}(y)+d_{G_{2}}^{2}(z)\right) .
\end{aligned}
$$

\section{References}

[1] Devilers J., Balaban A.T. (Ed), Topological indices and related descriptors in QSAR and QSPR, Gordon and Breach, Amsterdam, The Netherlands, 1999.

[2] Gutman I.,Polansky, Mathematical Concepts in Organic Chemistry, Springer-Verlag, Berlin

[3] Gutman I., Trinajstic N., Graph theory and molecular orbitals Total $\pi$ -electron energy of alternant hydrocarbons, Chem. Phy. Lett. 17(1972) 535-538.

[4] Khalifeh M.H., Yousefi-Azari H., Ashrafi A.R., The first and second Zagreb indices of some graph operations, Discrete Appl. Math 157(2009) 804-811.

[5] Feng L., Ilic A., Zagreb, Harary and hyper-Wiener indices of graphs with a given matching number, Appl. Math. Lett. 23(2010) 943-948.

[6] Gutman I., Das K.C., The first Zagerb index 30 years after, MATCH Commun. Math. Comput. Chem. 50(2004) 83-92.

[7] Ashrafi A.R., Doslic T., Hamzeha A., The Zagreb coindices of graph operations, Discrete Appl. Math. 158(2010) 1571-1578.

[8] Ashrafi A.R., Doslic T., Hamzeha A., Extremal graphs with respect to the Zagreb coindices, MATCH Commun. Math. Comput. Chem. 65(2011) 85-92.

[9] Doslic T., Vertex-weighted Wiener polynomials for composite graphs, Ars Math. Contemp. 1(2008) 66-80.

[10] Hua H., Zhang S., Relations between Zagreb coindices and some distance-based topological indices, MATCH Commun. Math.Comput. Chem. 68(2012) 192-208.

[11] Shirdel G.H., Rezapour H., Sayadi A.M., The hyper Zagreb index of graph operations, Iranian J. Math. Chem. 4(2013) 213-220.

[12] Gutman I., Furtuba B., Kovijanic Uukicevic Z and Popivoda, Zagreb indices and coindices, MATCH commun. Math. Compact. Chem. 74(2013) 5-16.

[13] Farahani MR., Computing the hyper-zagreb index of hexagonal nanotubes, J. Chem. and Materials Research. 2(2015), 16-18.

[14] Farahani MP., The hyper-zagreb index of $T U S C_{4} C_{8}((S)$ nanotubes, Int. J. Engg and Tech. Research. 2(2015), 16-18.

[15] Hua H., Zhang S and Xu K, Further results on the recentic distance sum, Discretre Appl. Math. 160(2012), 170-180

[16] Alon N, Eigenvalues and expanders, Combinatoria 6(1986), 83-96

[17] Gutman I., Distance in thorny graph, Publ. Inst. Math. 63(1998) 3136.

[18] Kathiresan K.M., Parameswaran C., Certain generalized thorn graphs and their Wiener indices, J. Appl. Math. Inform. 30(2012) 793-807.

[19] Lu P., Miao Y., Spectra of the subdivision-vertex and subdivision-edge coronae, arXiv: 1302.0457v2(2013).

[20] Walikar H.B., Ramane H.S., Sindagi L., Shirakol S.S., Gutman I., Hosoya polynomial of thorn trees, rods, rings, and stars. Kragujevac $J$. Sci. 28(2006) 47-56.

[21] Zhou B., On modified Wiener indices of thorn trees. Kragujevac $\boldsymbol{J}$. Math. 27(2005) 5-9.

[22] Doslic., splices, links and their degree weighted wiener polynomials Graph Theory Notes N.Y. 48(2009), 47-55.

[23] Sampathkumar E., Chikkodimath S.B., Semitotal graphs of a graph-I, J. Karnatak Univ. Sci. 18(1973) 274-280. 